\title{
IMPLEMENTATION OF CLINICAL PRACTICE GUIDELINES FOR THE TIMELY DETECTION AND DIAGNOSIS OF EATING DISORDERS IN ADOLESCENTS AND ADULTS IN THE OUTPATIENT AND PRIORITY DEPARTMENT OF A PUBLIC PSYCHIATRIC HOSPITAL IN COLOMBIA
}

Pertuz-Cortes, Carolina; Navarro-Jiménez, Eduardo; Laborde-Cárdenas, Carmen; Gómez-Méndez, Pedro; Lasprilla-Fawcett, Silvana

\begin{abstract}
Objective: To implement clinical practice guidelines (CPGs) for the timely detection and diagnosis of eating disorders in adolescents and adults in the priority outpatient department of a public psychiatric hospital in Barranquilla, Colombia. Barriers to access to the implemented guidelines were identified. Methods: For the identification of evidence-based CPGs to be implemented, systematic searches were carried out in international databases of development agencies or compilers of clinical practice guidelines, and in databases that contained scientific literature on issues related to eating disorders. Conclusions: The two guidelines shortlisted for the final selection by consensus of a multidisciplinary team at the hospital were the "Royal Australian and New Zealand College of Psychiatrists clinical practice guidelines for the treatment of eating disorders" and the "Guía de práctica clínica sobre trastornos de la conducta alimentaria de Catalunya", the latter being finally chosen by consensus. There are not yet CPGs implemented for health professionals in the priority outpatient department of Colombian hospitals for eating disorders.
\end{abstract}

\section{Keywords}

Clinical practice guidelines, Feeding and eating disorders, Guía de práctica clínica, Trastornos de la alimentación y la ingestión de alimentos 